\title{
Four Quadrants Integrated Transformers for Dual-input Isolated DC-DC Converters
}

\author{
Ouyang, Ziwei; Zhang, Zhe; Andersen, Michael A. E.; Thomsen, Ole Cornelius
}

Published in:

I E E E Transactions on Power Electronics

Link to article, DOI:

10.1109/TPEL.2012.2186591

Publication date:

2012

Link back to DTU Orbit

Citation (APA):

Ouyang, Z., Zhang, Z., Andersen, M. A. E., \& Thomsen, O. C. (2012). Four Quadrants Integrated Transformers for Dual-input Isolated DC-DC Converters. I E E E Transactions on Power Electronics, 27(6), 2697-2702. https://doi.org/10.1109/TPEL.2012.2186591

\section{General rights}

Copyright and moral rights for the publications made accessible in the public portal are retained by the authors and/or other copyright owners and it is a condition of accessing publications that users recognise and abide by the legal requirements associated with these rights.

- Users may download and print one copy of any publication from the public portal for the purpose of private study or research.

- You may not further distribute the material or use it for any profit-making activity or commercial gain

- You may freely distribute the URL identifying the publication in the public portal 


\title{
Four Quadrants Integrated Transformers for Dual-input Isolated DC-DC Converters
}

\author{
Ziwei Ouyang, IEEE members, Zhe Zhang, IEEE members, Michael A. E. Andersen, IEEE members \\ and Ole $\mathrm{C}$. Thomsen, IEEE members
}

\begin{abstract}
A common limitation of power coupling effect in some known multiple-input dc-de converters has been addressed in many literatures. In order to overcome this limitation, a new concept for decoupling the primary windings in the integrated multiple-winding transformers based on 3-dimensional (3D) space orthogonal flux is proposed in this letter. And thus a new geometry core and relative winding arrangements are proposed in accordance with the orthogonal flux decoupling technology. Due to the four secondary windings are arranged in a quadratic pattern at the base core plate with the two perpendicular primary windings, a name of "four quadrants integrated transformers" (FQIT) is therefore given to the proposed construction. Since the two primary windings are uncoupled, the FQIT allows the two input power stages to transfer the energy into the output load simultaneously or at any timemultiplexing scheme, which can optimize the utilization of input sources, simplify the system structure and reduce the overall cost, so they are attractive for the hybrid renewable power system. Section IV initiates a discussion for the advantages of the FQIT. In order to verify the feasibility of the FQIT in multiple-input converter, a dualinput isolated boost dc-de converter with the FQIT is designed and tested. The results have excellently demonstrated that the two input power stages can be operated independently and the correctness of all the analysis in the letter.
\end{abstract}

Index Terms - decoupling, dc-dc, integrated transformer, multiple-input converter (MIC), phase shift.

\section{INTRODUCTION}

$\mathrm{M}_{\mathrm{a}}^{\mathrm{L}}$ TIPLE-INPUT converters (MICs) have been proposed as ost-effective and flexible way to interface various sources such as solar array, wind turbine, fuel cell, and commercial ac line, to get a regulated output voltage, and in some cases, energystorage devices, with a load [1-4]. A common limitation of some known MICs is that only one input power source is allowed to transfer the power energy to the output at a time to prevent power coupling effect. Recently, in order to overcome this limitation, it has been proposed to use multiple- winding transformers based on flux additivity technology with phase-shifted PWM control [5]. This technology can transfer power from two or multiple different input voltage sources to the output load simultaneously meanwhile reverse blocking diodes are required at the input power stage sides. The reverse blocking diodes are needed to prevent a reverse power flow from one of the input voltage sources to another input voltage source through the coupled primary sides of the transformer as well as body diodes of semiconductor switches of the input power stages. Without these reverse blocking diodes, different input sources coupled to the multiple-input power converter cannot deliver power to the load

Manuscript submitted $2^{\text {th }}$ Oct. 2011 , revised $23^{\text {th }}$ Nov.2011, and accepted $26^{\text {th }}$ Jan. 2012. This work has been filed as EU\&US patent and is supported by Flux A/S. The corresponding author Ziwei Ouyang, postdoc, is with the Department of Electrical Engineering, Technical University of Denmark, 2800 Kongens Lyngby, Denmark (e-mail: zo@elektro.dtu.dk).

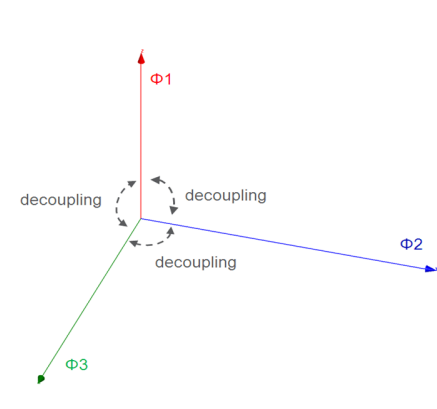

(a) (b)

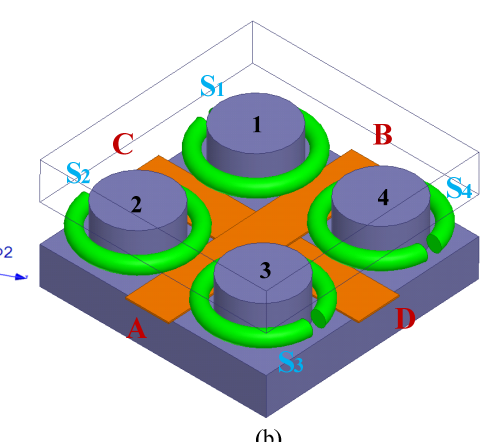

Fig. 1. (a) 3D space orthogonal flux decoupling; (b) proposed integrated transformer with four quadrants structure.

simultaneously. Furthermore, this technology cannot be applied in the buck type isolated MICs unless the input voltages are strictly limited according to the turns ratio of multiple primary windings. Otherwise, an undesirable voltage difference stresses on one of the input power stages, causing an extremely high current on the semiconductors and thus damages the circuit. In addition, some other prior art approaches nowadays to overcome this limitation result in a large number of power switches and complicated control schemes [6], [7].

The main reason for the problem in the MICs is the multiple primary windings are coupled. Consequently, it would be advantages to provide an integrated transformer with uncoupled primary windings for use in the MICs to allow multiple input power sources to be operated independently without compromising any functions of the power converter or required complex control or protection circuitry to be added to the input power stages. However, the existing decoupling approaches applied to the traditional core geometries such as E-I or E-E rely on a shared lower reluctance path or flux cancellation mechanisms [8]. In practical, both approaches applied to the traditional cores will cause lower magnetizing inductances, higher winding loss and EMI problem [9], [10], [11]. Hereby, this letter proposes a new flux decoupling concept for the multiplewinding transformers used in the MICs. As shown in Fig. 1-(a), the new flux decoupling concept is based on 3-dimensional (3D) space orthogonal flux decoupling wherein the three flux paths extend substantially orthogonally to each other within the shared magnetically permeable core. This requires a sort of nontraditional core geometries to carry out the orthogonal flux paths, shown in Fig. 1-(b). Since this letter focuses on a new idea and its specific contributions rather than a detailed circuit analysis for its applicable topologies, the construction of this letter is accordingly organized as follows: Section II briefly presents the modeling of the proposed integrated FQIT transformer. Section III describes an operational principle of the FQIT used in dual-input isolated boost dc-dc converter. Section IV initiates a discussion of the advantages of the proposed transformer. In order to verify the 


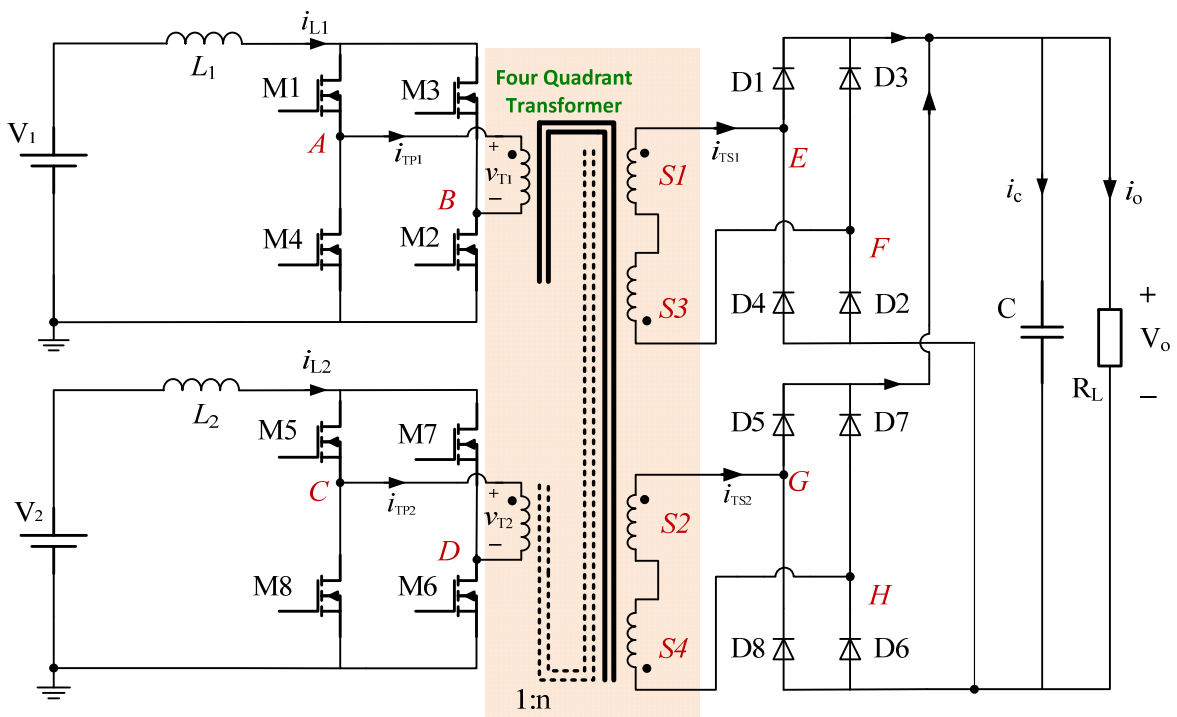

Fig.3. Dual-input isolated boost dc-dc converter with four quadrant integrated transformer.

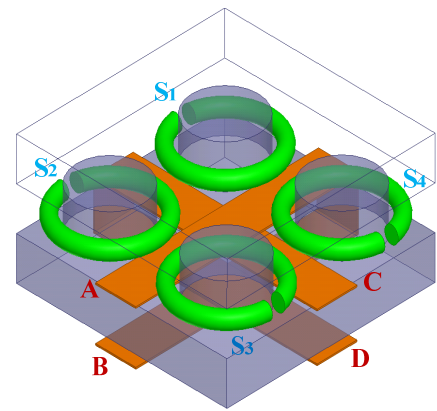

(a)

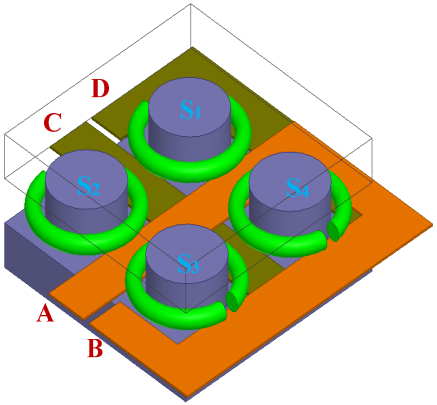

(b)
Fig.2. Available structures for plurality turns of (a) vertical directed (b) horizontal directed primary windings.

feasibility of the proposed transformer and the correctness of its analysis, an experimental dual-input isolated boost $\mathrm{dc}-\mathrm{dc}$ converter employed with the proposed integrated transformer has been built. The experimental results are shown in Section V.

\section{MODELING OF FOUR QUADRANTS INTEGRATED TRANSFORMER}

As shown in Fig. 1-(b), the magnetically permeable core comprises of a base rectangular core plate with four legs situated at respective corners, and a top rectangular core plates. In order to clearly illustrate the winding arrangements, a transparent top core plate is drawn in Fig. 1-(b). The first primary winding $A B$ and the second primary winding $C D$ are orthogonally arranged as a crossshaped layout in-between the four legs. By using the right hand rule, the flux generated from winding $A B$ is substantially orthogonal to the flux generated from winding $C D$ in the base and top core plates, and thus the uncoupled primary windings are constructed. The four legs provide a shared magnetic flux path to the two primary windings where the four secondary windings, $S_{l}$, $S_{2}, S_{3}$ and $S_{4}$, are wound in each respectively. Therefore, the two primary windings are both coupled with the four secondary windings. A name of "four quadrants integrated transformer" (FQIT) is given to the proposed integrated transformer since the four legs with enclosed secondary windings are arranged in a quadratic pattern at the base core plate with the two perpendicular primary windings. The plurality turns of primary windings can be

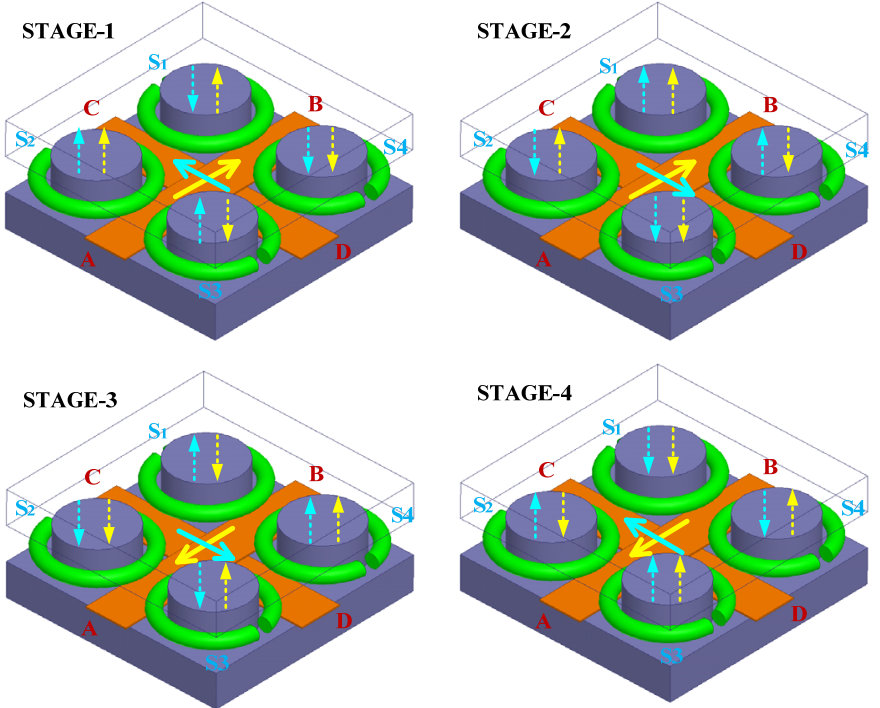

Fig.4. Four stages of flux directions through the legs.

arranged as shown in Fig. 2 (a) and (b).

\section{OPERATION PRINCIPLE OF FOUR QUADRANTS INTEGRATED TRANSFORMER}

This transformer can be used in many different topologies employing the multiple-winding transformers. In order to describe a basic principle of the FQIT, a dual-input isolated boost dc-dc converter is given in Fig. 3 as an example. In the secondary side, the windings wound in the diagonal legs, $S_{1}$ and $S_{3}, S_{2}$ and $S_{4}$ are connected in series with a reverse coupled winding direction. The respective series-wound are electrically coupled to their individual rectifiers and then in parallel connected to the output load.

The direction and amplitude of the magnetic fluxes in the legs are dependent of the magnetizing currents of the primary windings. Accordingly, the four stages of the magnetic fluxes through the legs in accordance with the magnetizing current states have been depicted in Fig. 4. The directions for the magnetizing currents of the primary windings, $i_{T 1}$ and $i_{T 2}$, are indicated by 


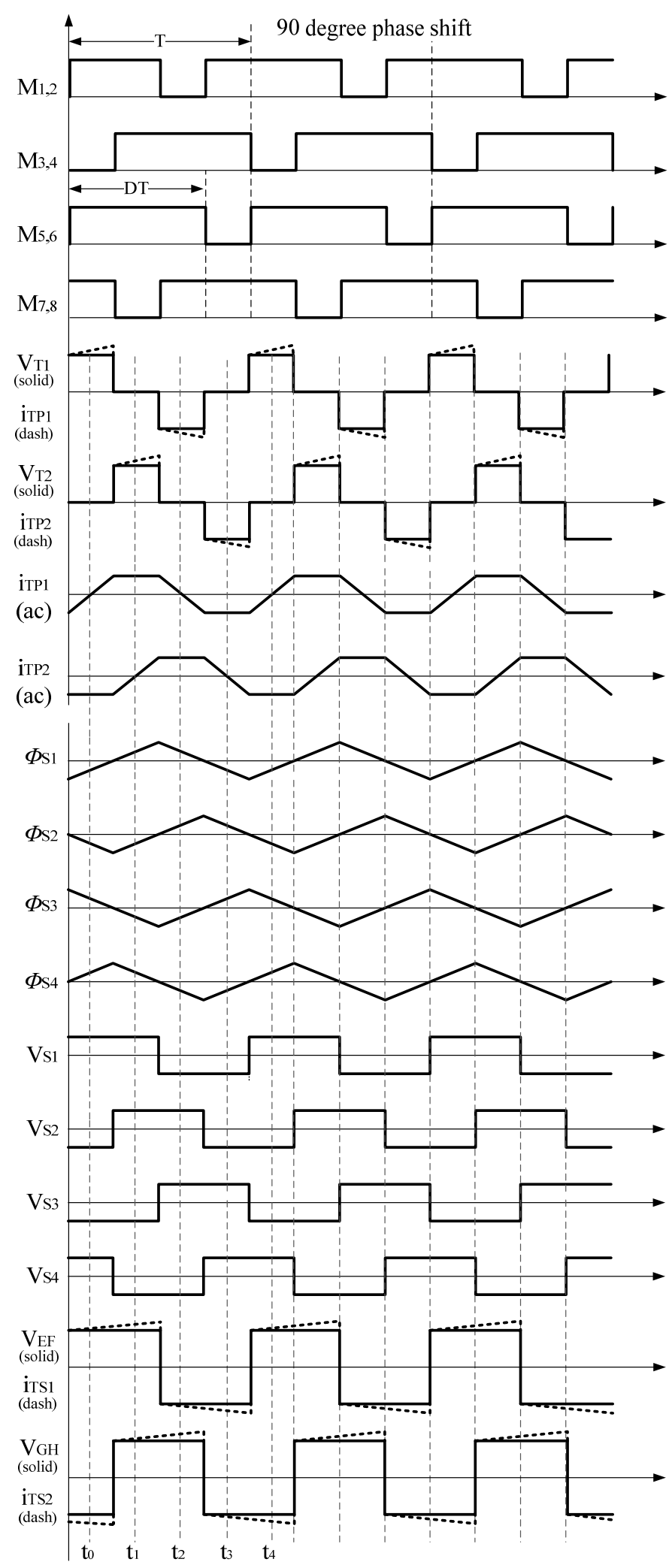

Fig.5. Timing diagram and basic waveforms for the four quadrants integrated transformer.

solid arrows. The corresponding magnetic fluxes through the four legs induced by the two currents are indicated by the dash arrows respectively. Due to the full-bridge boost converter, the duty cycle must be operated above $50 \%$ to ensure switch overlap and thus a continuous current path for the boost inductor current.
Accordingly, typical primary voltage waveforms $V_{T 1}$ and $V_{T 2}$ with zero voltage platforms are produced as depicted in Fig. 5 and a $75 \%$ duty cycle is given as an example.

1) STAGE-1 $\left(t_{0}-t_{1}\right)$, the magnetizing current, $\mathrm{i}_{\mathrm{T} 1}$, is positive and the magnetizing current, $\mathrm{i}_{\mathrm{T} 2}$, is negative. This currents state is characterized by the indicated direction shown in Fig. 4-(a). Using the right hand rule, the current $\mathrm{i}_{\mathrm{T} 1}$ leads to the magnetic fluxes in the leg 1 and leg 2 (Leg 1 is the leg corresponding with the winding S1. The rest may be deduced by analogy) flowing along the same direction indicated by the yellow dash arrows. This is a consequence of the leg 1 and the leg 2 being arranged on the same side of the primary winding AB. Furthermore, the current $i_{\mathrm{T} 1}$ also leads to the magnetic fluxes in the leg 3 and leg 4 flowing along the same direction. The magnetic fluxes induced by the current $i_{\mathrm{T} 1}$ leads to oppositely directed fluxes in the leg 1 and leg 2 relative to the leg 3 and leg 4 which is a consequence of the geometry of the closed magnetic flux loop. Likewise, the current $i_{\mathrm{T} 2}$ leads to the same flux directions in the leg 1 and leg 4 indicated by the blue dash arrows. The opposite flux direction relative to the flux direction in the leg 1 and leg 4 are induced in the leg 2 and leg 3 by the current $i_{\mathrm{T} 2}$. Hereby, a flux cancellation can be observed in the leg 1 and leg 3, meanwhile an overlapped flux occurs in the leg 2 and leg 4.

2) $S T A G E-2\left(t_{1}-t_{2}\right)$, the magnetizing currents, $i_{T 1}$ and $i_{T 2}$, are both positive. This currents state is characterized by the indicated direction shown in Fig. 4-(b). The magnetic fluxes induced by the current $i_{T 1}$ through all four legs keep the same directions with those produced in the stage- 1 since the direction of the current $i_{T 1}$ is not changed. However, as the direction of the current $i_{T^{\prime} 2}$ is changed, the directions of the induced magnetic fluxes indicated by the blue dash arrows are accordingly changed. Hereby, a flux cancellation can be observed in the leg 2 and leg 4, meanwhile an overlapped flux occurs in the leg 1 and leg 3.

3) STAGE $3\left(t_{2}-t_{3}\right)$, the magnetizing current, $i_{T 1}$, becomes negative and the magnetizing current, $i_{T 2}$, still keeps positive. This currents state is characterized by the indicated direction shown in Fig. 4-(c). All magnetic fluxes induced by the currents $i_{T 1}$ and $i_{T 2}$ are reversed relative to those induced in the stage- 1 .

4) $S T A G E 4\left(t_{3}-t_{4}\right)$, the magnetizing currents, $i_{\mathrm{T} 1}$ and $\mathrm{i}_{\mathrm{T} 2}$, are both negative. This currents state is characterized by the indicated direction shown in Fig. 4-(d). All magnetic fluxes induced by the currents $i_{\mathrm{T} 1}$ and $\mathrm{i}_{\mathrm{T} 2}$ are reversed relative to those induced in the stage-2.

Overall, a cancelled flux and an overlapped flux can be always observed in the each pair of diagonal legs respectively. Since there is a $90^{\circ}$ degree between the two excitation currents and $75 \%$ duty cycle, the triangular flux waveforms through each leg can be plotted in Fig. 5 where $\Phi_{\mathrm{S} 1}, \Phi_{\mathrm{S} 2}, \Phi_{\mathrm{S} 3}$ and $\Phi_{\mathrm{S} 4}$ represent the overall flux through each secondary winding $\mathrm{S}_{1}, \mathrm{~S}_{2}, \mathrm{~S}_{3}$ and $\mathrm{S}_{4}$ respectively. This implies that square voltages with $50 \%$ duty cycle are produced in each secondary winding as symbols $\mathrm{V}_{\mathrm{S} 1}$, $\mathrm{V}_{\mathrm{S} 2}, \mathrm{~V}_{\mathrm{S} 3}$ and $\mathrm{V}_{\mathrm{S} 4}$ in Fig. 5.

For the different phase shift angle between the two input power stages, the induced voltage waveforms on each secondary winding can be obtained by using the aforementioned analytical approach. As shown in Fig.6, not only the shapes but also the amplitudes of the voltages are changed. The maximum output voltage for the dual-input isolated boost dc-dc converter is achieved in the cases of $0^{\circ}$ and $180^{\circ}$ phase shift. The minimum voltage is obtained in the case of $90^{\circ}$ phase shift and the case of $45^{\circ}$ phase shift causes an output voltage in between. In fact, this characteristic of the flux cancellation and adding in each pair of 

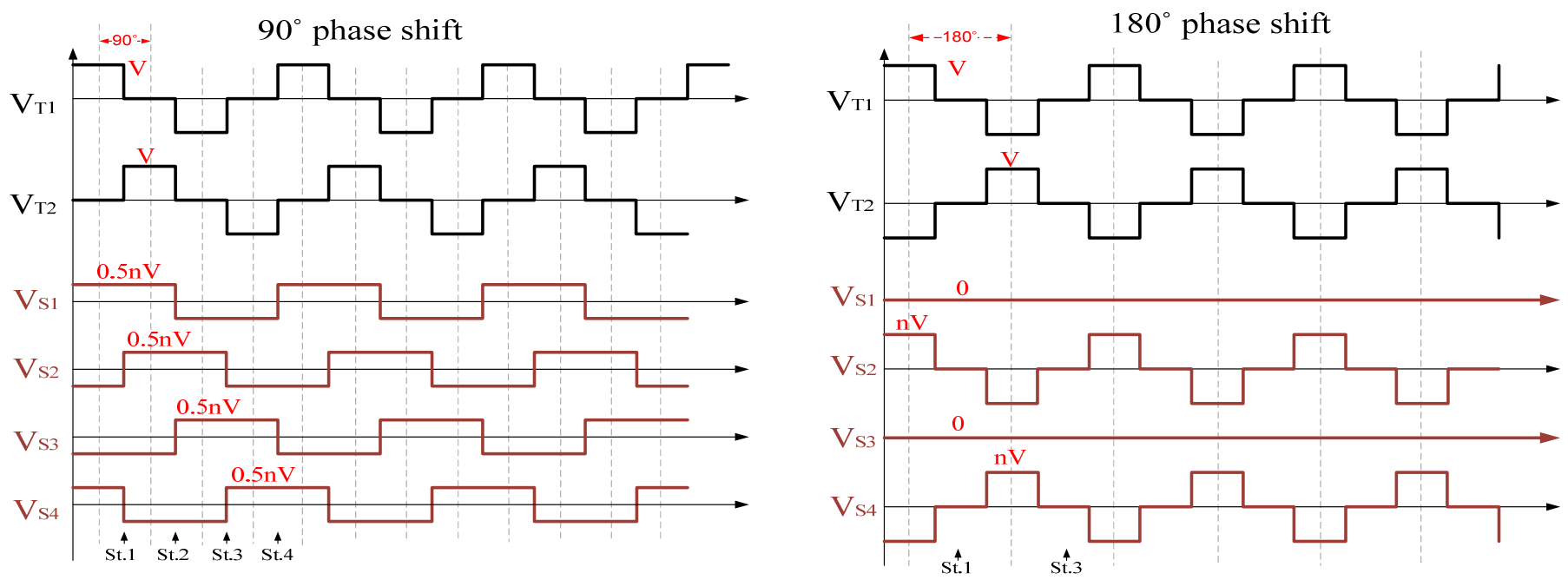

$0^{\circ}$ phase shift
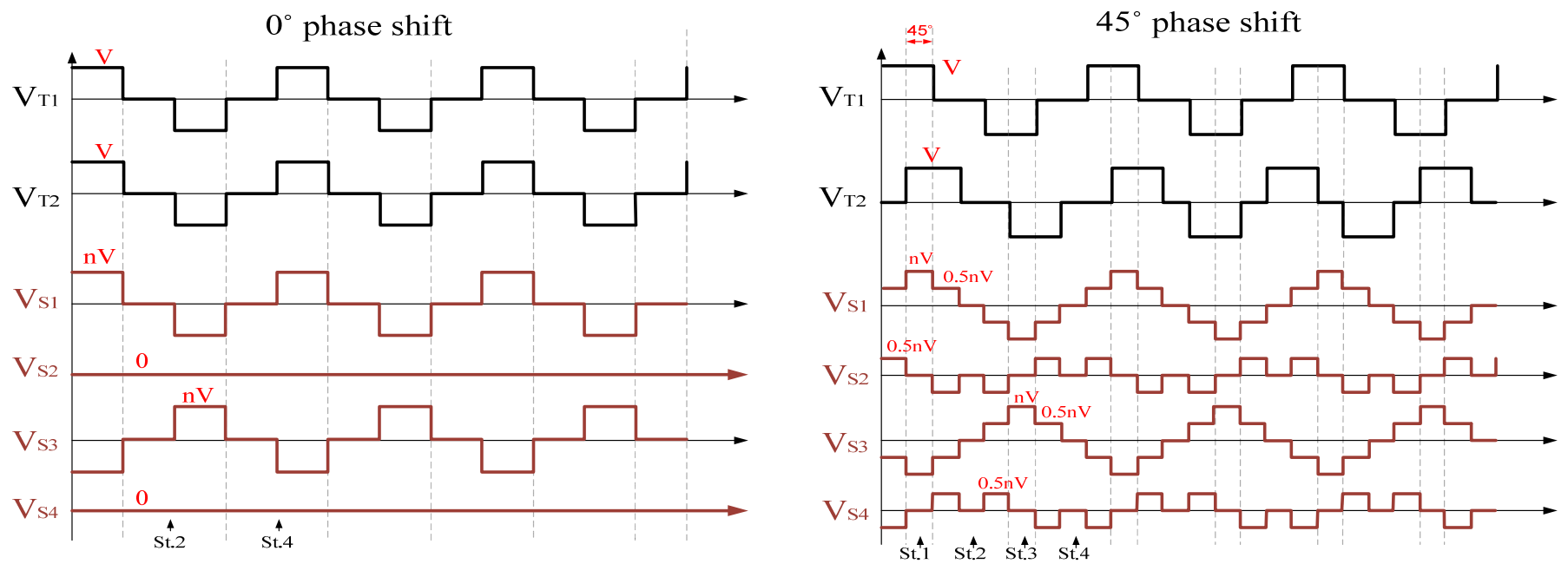

Fig.6. Induced secondary voltages in each leg for different phase shift angles between two input power stages.

diagonal legs effectively changes turns ratio of the transformer. Accordingly, the output voltage can be controlled by the phase shift angle. The function of voltage gain in the converter cannot simply described by the duty cycle and turns ratio since the phase shift angle has to be considered. The detailed function relationship of voltage gain specified to this converter will be analyzed in the future continued publication.

\section{Discussion of Advantages}

\section{A. Independent operation}

Since the two primary windings $A B$ and $C D$ are uncoupled, the two input power stages have the common ground and can be operated independently where the two input power sources are allowed to transfer the energy into the output simultaneously or at any time-multiplexing scheme. Meanwhile, the two power stages can be operated in different input voltage levels due to its independent operation. These advantages enable an operational reliability for the dual-input converter when any faults occur in one of the input power stages. Currently, these features cannot be implemented efficiently by using the traditional multiple-winding transformers with the flux additive. Furthermore, the FQIT can be applied in any type of topologies associated with multiple inputs. In addition, two discrete transformers with special- connected secondary are used to generate the complementary pulse-width and thus solve the cross-regulation problem for the dual-output converters [12], [13]. The proposed FQIT may have a potential to overcome the cross-regulation problem without using complex control method for the dual-output converters.

\section{B. Cost-effective, low size and high efficiency}

Unlike a conventional multiple-input converter, the FQIT features minimized number of magnetic components without adding extra auxiliary circuit and switches. Hereby, this is a costeffective way to implement the dual-input converter. Certainly, a lower size for the converter can be obtained as well. Furthermore, the flux cancellation occurring in the magnetic core may cause a lower core loss compared to the solutions with the discrete magnetic components, and thus a higher efficiency may be achieved.

\section{Wide range input/output voltages}

The output voltage is not only controlled by the duty cycle of PWM signal but also controlled by the phase shift angle between the two input power stages. If a combination of duty cycle control and phase shift control is used in the dual-input converter, a wider range of input or output voltages accordingly can be achieved. 


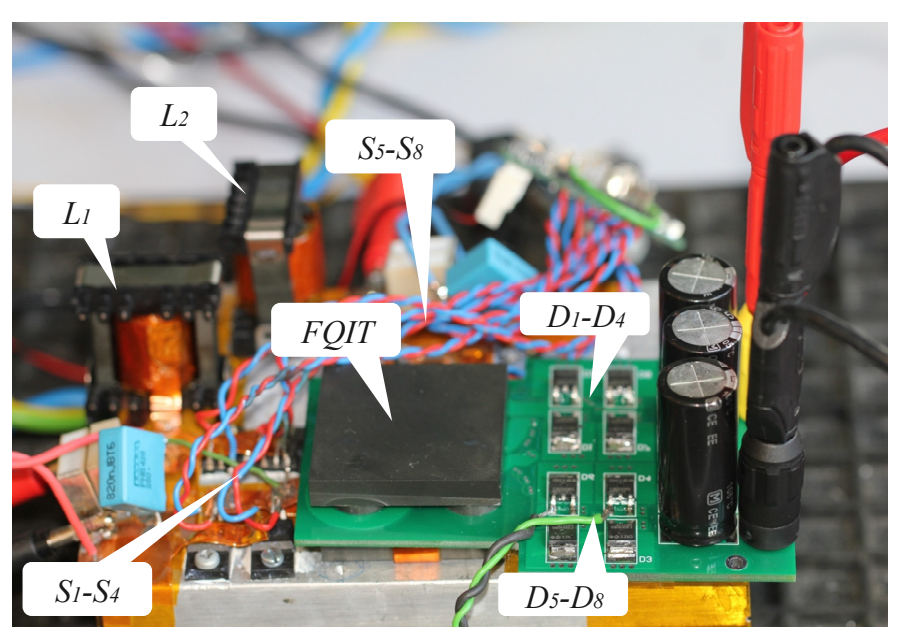

Fig.7. Photo of experimental prototype with the FQIT.

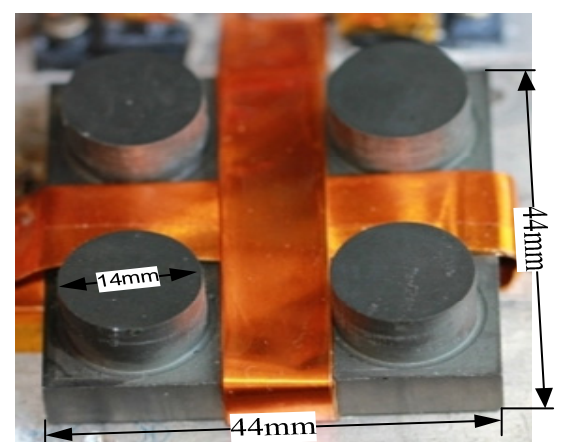

(a)

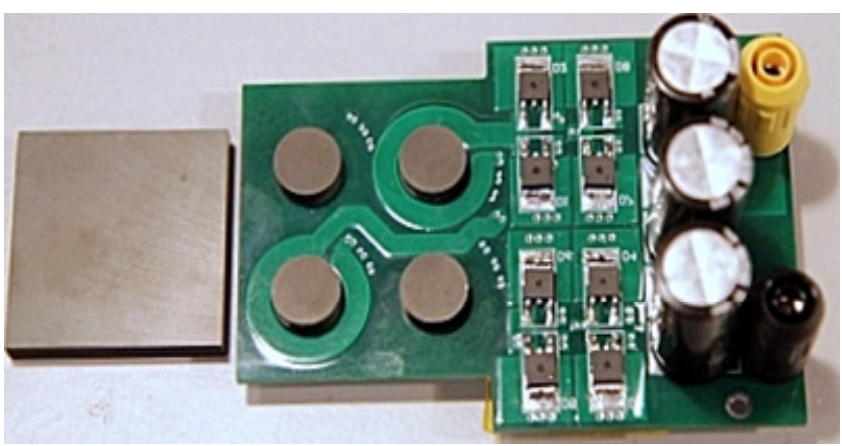

(b)

Fig. 8. Sub-pictures of the FQIT (a) primary windings (b) secondary windings.

\section{Waveforms characteristics}

$50 \%$ duty cycle square waveforms without zero voltage platforms are induced on each secondary winding when the phase shift angle is $90^{\circ}$. Ideally, zero voltage ripple can be achieved in the load without any output capacitor. In addition, the current stress on the semiconductors of secondary side can be significantly reduced since the multi-level voltage waveforms are induced when the phase shift angle is $45^{\circ}$. Moreover, since different output voltage waveforms are induced in the secondary windings as the different phase shift angle between the two input power stages, it may extensively derive some improved configurations for specific application.

However, the disadvantages of the FQIT are that the special core manufacture is needed and this winding structure may cause

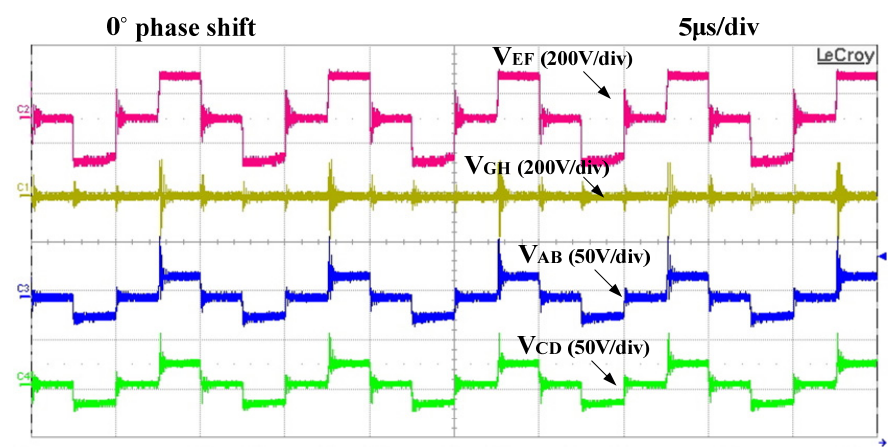

(a)

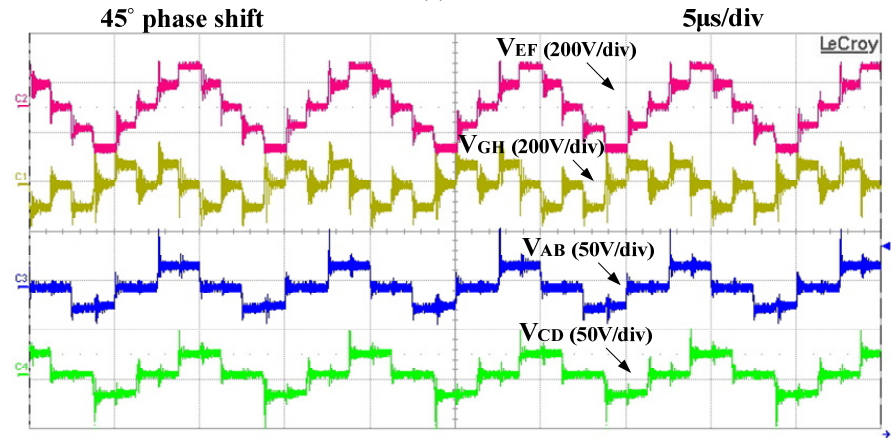

(b)

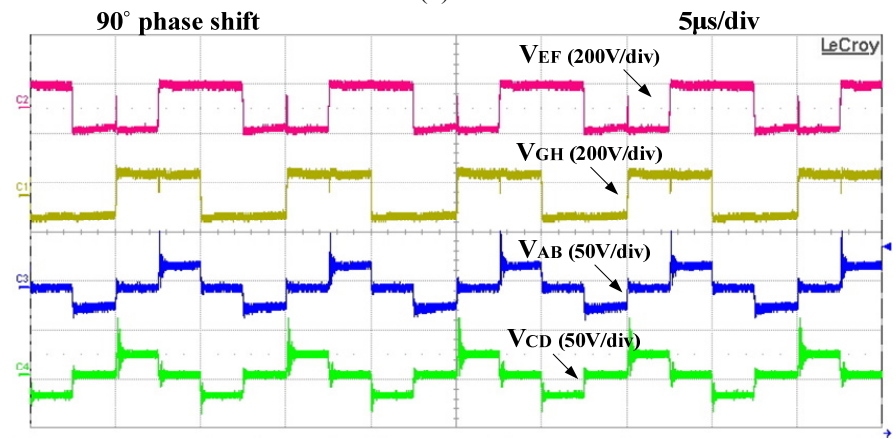

(c)

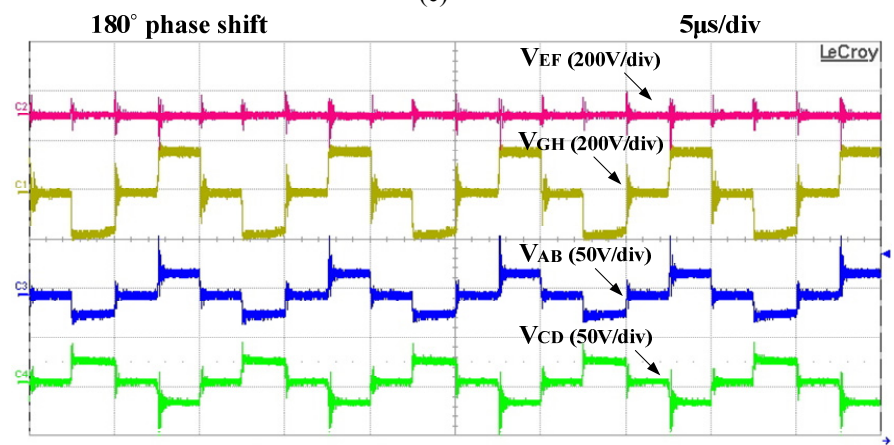

(d)

Fig.9. Experimental waveforms for different phase shift angles.

a higher leakage inductance than that of the traditional transformers.

\section{V.EXPERIMENTAL VERIFICATION}

In order to verify the correctness of the above analysis, a proofconcept experimental prototype with the proposed FQIT has been built. Fig. 7 shows the photo of the experimental prototype and the dimension of the employed FQIT and its sub-picture are shown in Fig. 8. Mn- $\mathrm{Zn}$ ferrite is used as the material of magnetically permeable core. For simplification, one turn copper foil is used in the both primary sides and four turns are used in each secondary winding which are implemented by the PCB 
winding. The switching frequency is operated at $100-\mathrm{kHz}$. The experimental results have excellently demonstrated that the two input power stages can be operated independently. Two terminal voltages of the primary windings, $\mathrm{V}_{\mathrm{AB}}$ and $\mathrm{V}_{\mathrm{CD}}(\mathrm{CH} 3 \& \mathrm{CH} 4)$, and two terminal voltages of the series-secondary windings, $\mathrm{V}_{\mathrm{EF}}$ and $\mathrm{V}_{\mathrm{GH}}(\mathrm{CH} 1 \& \mathrm{CH} 2)$, are presented in Fig. 9. The two input dc voltages are both $12.5-\mathrm{V}$ and the duty cycle are kept $75 \%$. The output voltage can be adjusted by shifting the phase angle between the two power stages. Maximum 200-V output voltage is obtained when the phase angle is $0^{\circ}$ or $180^{\circ}$. Minimum $100-\mathrm{V}$ output voltage is obtained when the phase angle is $90^{\circ}$, and around $141-\mathrm{V}$ output voltage is obtained when the phase angle is $45^{\circ}$. As seen in these plots, the experiment results have demonstrated the correctness of the analysis in Section III.

\section{CONCLUSION}

This letter proposes a new concept for decoupling the primary windings in the integrated multiple-winding transformers based on 3-dimensional (3D) space orthogonal flux decoupling. Only two orthogonal flux paths are utilized in the proposed four quadrants integrated transformer and an applicable geometry of 3D orthogonal flux decoupling can be found in [14]. The proposed FQIT allows the two input power stages to transfer the energy into the output simultaneously or at any time-multiplexing scheme. This enables a solution to the limitation of the traditional multiple-input converters. Many advantages of the FQIT such as cost-effective, low size and high efficiency have been discussed. In addition, wider range input/output voltages may be achieved since the phase shift between the two input power stages can be used to control the output voltage. This letter gives an applicable example of isolated boost dc-dc converter for the proposed FQIT. From the authors' points of view, the interesting waveforms induced on the secondary windings with the phase shift control may arouse some improved topologies development for specific application in future works.

\section{REFERENCES}

[1] Y-C. Liu, Y-M. Chen, "A systematic approach to synthesizing multi-input dc-dc converters," IEEE Trans. on Power Electron., vol.24, no.1, pp.116127, Jan. 2009

[2] K. Kobayashi, H. Matsuo, and Y. Sekine, "Novel solar-cell power supply system using a multiple-input DC-DC converter," IEEE Trans. on Ind. Electron., vol. 53, no. 1, pp. 281-286, Feb. 2006.

[3] H. Matsuo, T. Shigemizu, F. Kurokawa, N. Watanabe, "Characteristics of the multiple-input dc-dc converter," IEEE Trans. on Ind. Electron., vol.51, no.3, pp. 625- 631, June 2004

[4] K. P. Yalamanchili, M. Ferdowsi, "Review of multiple input dc-dc converters for electric and hybrid vehicles," in Proc. IEEE Vehicle Power and Propulsion Conference, pp. 160- 163, 7-9 Sept. 2005

[5] Y-M. Chen, Y-C. Liu and F-Y. Wu, "Multi-input dc/dc converter based on the multiwinding transformer for renewable energy applications" IEEE Transactions on Ind. Appl., vol.38, no.4, pp. 1096- 1104, July 2002.

[6] J. Ruan, F. Liu, X. Ruan, D. Yang, Y. Li and K. Jin, "Isolated multiple-input $\mathrm{dc} / \mathrm{dc}$ converter using alternative pulsating source as building cells," in Proc. IEEE IPEC, pp.1463-1470, 2010.

[7] H-J. Chiu, H-M. Huang, L-W. Lin and M-H. Tseng, "A multiple-input dc/dc converter for renewable energy systems," in Proc. IEEE ICIT, pp.13041308, Dec. 2005

[8] Z. Ouyang, "Advances in planar and integrated magnetics," $\mathrm{PhD}$ dissertation, ISBN: 978-87-92465-88-7, 2011.

[9] S. S. Ochi and E. H. Wittenbreder, "Integrated multi-transformer" US patent, US20090230776A1.

[10] L. Yan, D. Qu and L. B, "Integrated magnetic full wave converter with flexible output inductor," IEEE Trans. on Power Electron., vol.18, no.2, pp 670- 678, Mar 2003.

[11] D. Cheng, L-P. Wong, and Y-S. Lee, "Design, modeling, and analysis of integrated magnetics for power converters," in Proc. IEEE PESC, pp:320325,2000 .
[12] Y. Chen and Y. Kang, "A fully regulated dual-output dc-dc converter with special-connected two transformers (SCTTS) cell and complementary pulsewidth modulation-PFM (CPWM-PFM)," IEEE Trans. on Power Electron., vol.25, no.5, pp. 1296- 1309, May 2010.

[13] Y. Chen and Y. Kang, "An improved full-bridge dual-output dc-dc converter based on the extended complementary pulsewidth modulation concept," IEEE Trans. on Power Electron., vol.26, no.11, pp. 3215-3229, Nov., 2011.

[14] Z. Ouyang, M. A. E. Andersen and Z. Zhang, "Four quadrants transformers" US\&EU patent, 2011, P1099US00 (pending). 